\title{
Developing science students' metacognitive problem solving skills online
}

\author{
Rowan W. Hollingworth and Catherine McLoughlin \\ The University of New England
}

Technology is increasingly being harnessed to improve the quality of learning in science subjects at university level. This article sets out, by incorporating notions drawn from constructivist and adult learning theory, a foundation for the design of an online environment for the acquisition of metacognitive problem solving skills. The capacity to solve problems is one of the generic skills now being promoted at tertiary level, yet for many learners problem solving remains a difficulty. In addition, there are few instances of instructional design guidelines for developing learning environments to support the metacognitive skills for effective problem solving. In order to foster the processes of metacognitive skills explicitly in first year science students, we investigated areas where cognitive support was needed. The aim was to strengthen the metacognitive and reflective skills of students to assist them in adopting strategies and reflective processes that enabled them to define, plan and self monitor their thinking during problem solving. In tertiary science, both well-structured and illstructured problems are encountered by students, thus a repertoire of skills must be fostered. A model for supporting metacognitive skills for problem solving is presented in the context of an online environment being developed at the University of New England.

\section{Introduction}

As information and communications technologies for both on campus and distance education students are developed, progress is being made in using ICT to teach science at the university level in exciting and engaging ways. In chemistry, for instance innovative, interactive visualisation programs give students vastly improved opportunities to understand processes occurring at the molecular level (Kozma et al, 2000). In many science subjects simulations of processes and experiments allow students to explore concepts in new ways, enabling students to become self directed learners. For example, the Cognition and Technology Group at Vanderbilt 
has developed and evaluated multimedia based instruction designed to help students to think, reason and solve problems (Vye et al, 1998).

Networked learning environments enabling student-student and studentlecturer communications are now open, flexible and more democratic through the use of email, bulletin boards and chat rooms, while students enjoy the autonomy of gaining access to expertise worldwide through Internet resources. However, structured learning environments that support specific skills relevant to problem solving in science are much needed. In response to this, there is also a growing emphasis on developing higher order cognitive skills of university science students (Barouch, 1997; Sleet et al, 1996; Bucat \& Shand, 1996). Essentially what matters most in learning in the sciences is the capacity to analyse and classify data, to gather evidence about solutions, to solve problems and to apply and test theories. Clearly, the knowledge base in science is expanding too fast to ensure that students cover all aspects of scientific knowledge within the duration of a university course. The alternative is to offer students learning experiences that allow for conceptual exploration and acquisition of thinking skills needed for their future learning (McLoughlin \& Luca, 2000; McLoughlin \& Oliver, 1998). It is on this assumption that we seek to develop an online environment for development of metacognitive skills.

\section{Metacognitive problem solving defined}

The term metacognition refers to a learner's knowledge about his or her processes of cognition and the ability to control and monitor those processes as a function of the feedback the learner receives via outcomes of learning (Metcalfe \& Shimamura, 1994). Thus, two essential components comprise metacognition: knowledge and control. Meta-cognitive knowledge refers to what a learner understands and believes about a subject matter or a task, and the judgments s/he makes in allocating cognitive resources as a result of that knowledge (Flavell, 1976; Brown, 1987). Metacognitive control refers to the approaches and strategies a learner devises to achieve specific learning goals and the degree to which the learner organises, monitors, and modifies those operations to ensure that learning is effective (Jacobs \& Paris, 1987).

With regard to metacognitive control, attention resources, existing cognitive strategies, and awareness of breakdowns in comprehension are all enhanced by metacognitive knowledge and skills (Schraw \& Dennison, 1994). Learners who use both improve their academic performance. Thus, metacognition is important to an understanding of learning in the sciences 
because learners must regulate their cognitive tactics and strategies in order to construct meaning from their reading, lectures, and laboratory experiences. Moreover, as science, physics, chemistry, biology, etc. are new and relatively unfamiliar informational fields, learners have to be more active, exploratory and self regulated during the comprehension building process (Tergan, 1997). These skills need to be taught and monitored as part of the instructional process.

\section{Fostering problem solving skills: Moving on from traditional approaches}

There is a vast literature on problem solving in the sciences, which remains a largely untapped resource by tertiary educators and instructional designers (Gabel \& Bunce, 1994). Futhermore, most instructional design approaches to fostering higher order skills do not reflect constructivist approaches to learning (Hedberg et al, 1998). Traditionally, problem solving has been presented by lecturers and tutors simply doing problem and then asking students to do similar problems. Even at the lower order cognitive skill levels of knowledge, understanding and application, students often experience real difficulties with routine problem solving. The usual process adopted involves "chug and plug" find the right formula, put the data into it and accept whatever answer comes out of the calculator. Typical problems are usually routine applications of formulae rather than real life problems, and it has been assumed that students will reach conceptual understanding just through sufficient practice at problem solving (Hobden, 1998). At best, by repetitive practice at problem solving many students will gain routine expertise, but not adaptive expertise (Hatano \& Inagaki, 1986). That is, they may develop speed and accuracy at routine problem solving, but fail to develop the ability to reflect on what they do or to adapt to solving new problems in a flexible manner by applying metacognitive skills.

Much of the research literature on training of metacognition concentrates on primary and secondary school students, there being much less related to university students. Examples of studies at the university level include, in the science area (Volet, 1991) a study of first year computer science students incorporating students' development a of a metacognitive strategy relevant to computer programming together with modelling and coaching its use in a socially supportive environment. Zeegers et al (1998) provide a self directed learning program to develop transferable learning and metacognitive skills for first year chemistry students. Outside the science area, Masui \& De Corte (1999) examined the trainability and effect 
on academic performance of enhancing learning and problem solving skills of business economics students. Each of these studies were long term interventions over a period of at least one semester using lecturers and tutors in face to face situations. The findings of these studies have been used to inform the development of an online supportive environment for metacognitive skill development at the University of New England.

\section{Context of the research: Student difficulties with problem solving}

At the University of New England we are developing a tutorial to strengthen the metacognitive skills in problem solving of first year science students. The tutorial is being built online in a WebCT environment and has components involving topics in Biology, Biophysics and Chemistry, the three subjects which constitute core subjects in first year science. In designing the tutorial we needed it to be suitable for use both by internal and external students.

The literature attests to the fact that even at tertiary level, few students appear to have developed expert problem solving skills that enable them to cope effectively with learning independently and effectively in the sciences (Volet et al, 1995; Everson \& Tobias, 1998; Gourgey, 1998). There is little planning, checking of answers or understanding of the meaning of the answers obtained. Often, when problem solving processes are emphasised, students express a desire just to be shown the right way to solve the problem.

Many students have rather primitive theories of learning and they demonstrate an epistemological perspective at a stage called basic dualism by (Perry, 1970). This stage is characterised by passivity and dependence on authority to hand down the truth and dictate what is right or wrong. In contrast, expert problem solvers demonstrate advanced skills and are able to operate independently to plan, monitor and control their learning. Educational research affirms pedagogies and instructional approaches that emphasise the interaction of cognitive, metacognitive and affective components of learning. If tertiary educators only emphasise content and discrete skills, students may not develop the deep learning approaches that enable transfer of skills and knowledge to real world contexts (Mayer, 1998). 
In designing the tutorial, metAHEAD, our objectives were as follows:

- to support the development of the metacognitive skills and habits of reflection, essential for effective problem solving in the sciences

- to foster students' problem solving skills in first year science utilising the communicative and supportive features of a technology based environment

- to apply constructivist instructional design principles that can contribute to the development of an online environment to foster metacognition.

\section{Fostering metacognitive skills: What do students need?}

Clearly, skills development programs need to capture students' attention and motivate them to improve their skills while addressing the issues of direct concern. Further, there need to be longer term programs to develop skills and independence which will continue to be used and which can be transferred to other areas. One of the documented weaknesses of current approaches to metacognitive skill development is that little account has been taken of the individual learner's needs and intentions.

A preliminary analysis of Chemistry students at UNE in their first year of study showed that while students displayed many problem solving skills, they lacked some such as checking, planning and revising solutions (Table 1). Teaching students isolated skills is therefore of limited value unless they know what and why they are learning these and how they will benefit. Students must learn to choose appropriate strategies, and must learn how to direct and control their own learning. Much recent work links the research on problem solving to self regulation and self directed learning (Boekaerts et al, 2000).

Schoenfeld (1992; 1985) suggests that process based approaches to developing problem solving can trigger students' awareness of their own thinking processes. Prompting students with procedural questions may help foster greater self awareness and metacognition. Questions include: What exactly are you doing? Why are you doing it? How does it help you? Technological environments can support both aspects of metacognition by offering scaffolds in the form of:

- access to procedural prompts and scaffolding that assists problem solving (Woodcock, 1995) 
- models of effective and expert problem solving through video and audio clips

- process based reminders, scaffolds and reflective spaces where students are asked to document the processes and strategies they apply while actually solving problems (McLoughlin et al., 2000).

An example of these types of scaffolding is that afforded by the Scientific and Mathematical Areas for Refining Thinking (SMART Environments) as developed by Brown \& Campione, (1994) and Vye et al., (1998).

Table 1: Preliminary analysis of students' metacognitive problem solving strategies

\begin{tabular}{|c|c|}
\hline Strategies reported & Strategies not reported \\
\hline Applying knowledge & $\begin{array}{l}{ }^{*} \text { Checking meanings of } \\
\text { terms }\end{array}$ \\
\hline \multicolumn{2}{|l|}{$\begin{array}{l}\text { Analysing } \\
\text { Think about what question is actually asking } \\
\text { Identify what you have and what you want } \\
\text { Identify important/not important info }\end{array}$} \\
\hline \multicolumn{2}{|l|}{ Relating, Reorganising } \\
\hline $\begin{array}{l}\text { Applying knowledge or information } \\
\text { Trying to remember \& apply previous examples \& } \\
\text { knowledge that seem related } \\
\text { Identify equation to use } \\
\text { Know how to manipulate equations to get answer }\end{array}$ & $\begin{array}{l}\text { *Planning steps of a } \\
\text { solution }\end{array}$ \\
\hline $\begin{array}{l}\text { Analysing whether answer is reasonable } \\
\text { Checking units with those of answer }\end{array}$ & $\begin{array}{l}{ }^{*} \text { Connecting to prior } \\
\text { knowledge }\end{array}$ \\
\hline \multicolumn{2}{|l|}{ Lateral thinking } \\
\hline Visualising the problem & $\begin{array}{l}{ }^{*} \text { Drawing diagrams, } \\
\text { representations of problem }\end{array}$ \\
\hline \multicolumn{2}{|l|}{ Work backwards } \\
\hline $\begin{array}{l}\text { Understand the meaning of formulas } \\
\text { Understand worked examples. Do a similar problem }\end{array}$ & $\begin{array}{l}{ }^{*} \text { Checking by applying to a } \\
\text { new problem }\end{array}$ \\
\hline
\end{tabular}

\section{Training in metacognition: Implications for the design of the learning environment}

Gredler (1997) proposes three general conditions for successful instruction in metacognition. First, informed training as opposed to blind training is essential for any instruction concerning cognitive strategies. The situations and task demands where particular strategies may be appropriate must be made explicit to students and they need to be given activities to practise 
assessing the task and situational demands. Second, student assessment should reflect the kinds of metacognitive skills developed through the instruction, otherwise there will be little incentive for students to develop. Third, supports for engaging in metacognitive activities should be provided in the instruction.

Mayer (1998) suggests that successful problem solving depends on three components - skill, metaskill, and will - and that each of these components can be influenced by instruction. This accords with the belief that effective support of metacognitive skills need to recognise the interaction of cognitive, metacognitive and affective components of learning (Gourgey, 1998).

In Figure 1, a schematic overview of the pedagogical support needed for metacognitive development is depicted. In order to equip students with the skills required for problem solving, the environment needs to offer an orientation to problem solving, support for planning the task, selecting and applying strategies and supporting reflection. Each of these elements is supported by the research literature and incorporated in the metAHEAD online program developed at UNE.

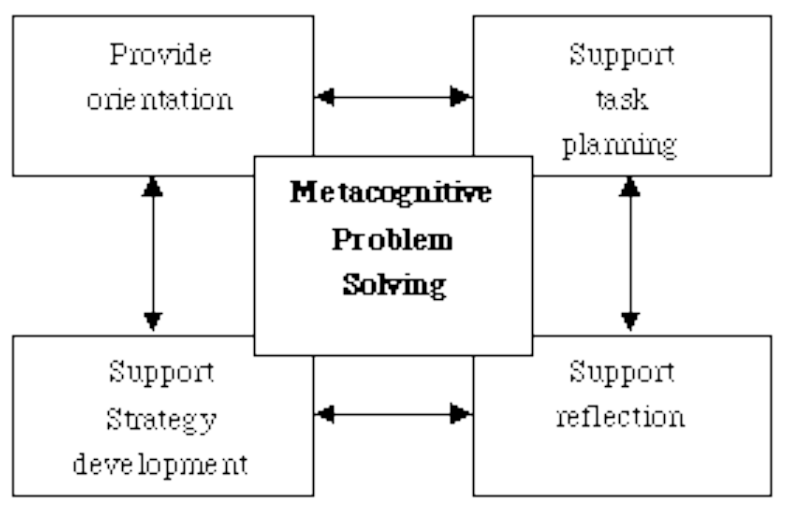

Figure 1: Support features for metacognitive training in metAHEAD

\section{Design stages for the online environment}

Based on extant research on metacognitive training, we propose a scheme for the development of metacognitive skills for science students that involves eight phases. The environment for metacognitive training 
combines Web based scenarios with problem simulations in order to engage learners in actual problem solving and reflection on their own problem solving strategies.

In Phase 1 the concept of metacognition is operationalised. For the problem in question, students need to become aware of the problem solving processes involved. For example this requires analysis of the question, planning a solution, selection of strategies and self monitoring skills that can be applied.

Phase 2 involves the design of the problem environment. For particular problems in a topic in Physics, for example, examine the different ways in which an expert and a novice student might answer the problem.

In Phase 3 the problem is then presented to the student to work on. Student responses are monitored in Phase 4 to decide if any intervention (Phase 5) is required.

Phase 5 presents students with a scenario or problem where they are assisted in the processes and procedures of problem solving, and made aware of their own problem solving strategies.

In Phase 6, successful students are presented with further problems in the topic area to check whether they have transferred the strategies learnt during Phases 3 and 4 . If they have not, training continues.

In Phase 7 students are given the opportunity to reflect on their problem solving.

The final Phase 8 involves a refinement of the training to create design guidelines for a problem solving environment in different subject areas (Biology, Physics or Chemistry) in order to foster metacognition.

\section{Instructional design principles applied to metAHEAD program}

How might these instructional design principles to develop metacognitive awareness and problem solving skills be implemented in a technological environment? In the design we have combined both constructivist and adult learning principles to foster student self direction on problem solving and reflection on the actual processes. 
The design of the technology based environment builds in three important implications of social constructivist theory concerning reflective thinking. First, in order to foster reflective thinking students need multiple sources of feedback on their understanding gained through social interactions. Second, reflective thinking will most likely occur in situations where problems are complex and meaningful to the student. Third, reflective thinking requires the student to organise, monitor and evaluate their thinking and learning to come to a deeper understanding of their own processes of learning. Bearing these aspects of reflection in mind, the technology based environment can provide scaffolds to enhance reflection through four types of feature (Lin et al, 1999; Elen \& Lowyck, 1999). metAHEAD offers support in the following processes:

Process displays: Students are explicitly shown what they are doing in performing a task. Both the processes used by the student and the responses created by the student will be made visible, thus enhancing self awareness.

Process prompting: Students explain what they are doing at different stages throughout their problem solving procedure.

Process modelling, Students have access to text, audio and video displays explaining what, how and why other students and experts do what they do in solving a specific problem.

Reflective social discourse: This is an online discussion space where students share their learning experiences and gain feedback from a community of learners.

\section{The project metAHEAD: An online tutorial to support metacognition}

By adopting constructivist and social interactionist theories we have aimed to make the most of the online environment to support students' interactions with each other through bulletin boards to discuss problem solving and to collaborate on tasks. A flow diagram of the tutorial is shown in Figure 2.

An introductory module introduces students to some basic ideas about learning and thinking, cognition and metacognition. At this stage students also do a metacognitive awareness inventory quiz. This preliminary module helps orient students and bring to their awareness their present level of metacognitive skills. We then use the typical assignment exercises and exam questions students come across in the study of their subjects to 
lead into metacognitive skills development. Our experience suggests that students are not likely to be interested in skills development programs unless they can see direct application to the work they are doing in their subjects at the time they are doing the program. Some students find it difficult to take a longer term approach to their general skills development.

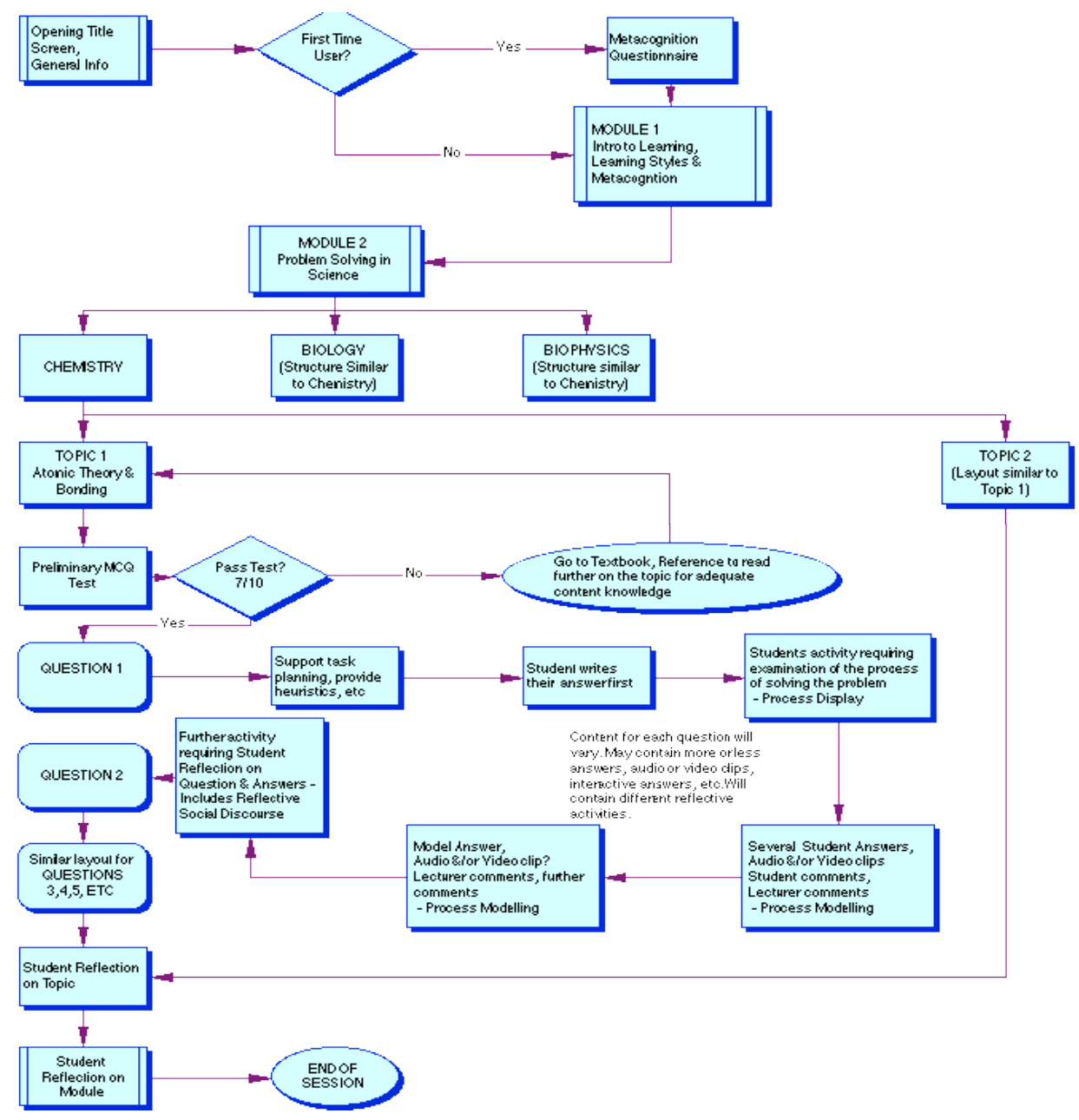

Figure 2: Flow chart diagram for metAHEAD tutorial 
In the tutorial the students may choose the subject and topic to work on. They are first given a quick multiple choice test on this topic to ensure they have a reasonable level of background knowledge to proceed any further. The point is that the tutorial is not aimed at developing subject knowledge and that students need a knowledge base to be able to tackle the problems being presented. The student is then asked to solve the problem, being presented with a variety of prompts and questions about the processes they engage in during their solution process. For different problems various supports such as heuristics are available to students and their use is encouraged. In this way we can expose students to a number of process displays and prompts. They then have a chance to view answers given by other students, ranging through poor to very good answers. A model answer from the lecturer is also available. All these answers are commented upon and students may also listen to audio clips or video clips of the other students and lecturers as they worked on the problems, giving insight into the skills they applied in their solutions. In this way metAHEAD offers process modelling to learners. By exposing students to the answers of other students to typical problems, we encourage them to reflect on their own level of use of metacognitive skills.

For some questions, students are asked to collaborate with each other to build a collaborative solution on the bulletin board. One of a range of reflective activities is presented to students at the completion of each problem. Here there is also the opportunity for further reflective social discourse through discussion of more general issues in bulletin board topics. Since there are a number of problems over the different subjects and topics, we have aimed to present a variety of displays, prompts and modelling, as well as associated learning and reflective activities with different problems.

On the other hand many of the same ideas are being applied, discussed and reflected upon in different questions in different topics and subjects, which we believe will assist in transfer of the skills developed to broader areas of application. Evaluation of the program will lead to further refinements.

\section{Conclusion: Supporting metacognition in the sciences}

The project described here is the initial phase of a two year teaching project dedicated to development of metacognitive skills in science. We believe that students' metacognitive skills can be developed significantly by taking a proactive approach and by designing an environment specifically for problem solving and metacognition. This project proposes that metacognition can be developed in contexts that engage students in 
self monitoring their own problem solving approaches, in scenarios where they can ultimately use that knowledge. This requires creating real life anchors for the development of problem solving skills and enabling students to explore, test and review their own strategies. Though the project is still in the initial phases, we anticipate that the research will result in significant changes to the way teaching in the sciences is currently conceptualised, while maximising the potential of online technologies.

\section{References}

Barouch, D. H. (1997). Voyages in Conceptual Chemistry. Sudbury, Mass: Jones \& Bartlett Publishers.

Boekaerts, M., Pintrich, P. R., \& Zeidner, M. (2000). Handbook of Self-Regulation. San Diego: Academic Press.

Brown, A. L. (1987). Metacognition, executive control, self-regulation, and other mysterious mechanisms. In F. K. Weinert, R. (Ed.), Metacognition, Motivation, and Understanding. New Jersey: Lawrence Erlbaum.

Brown, A. L. \& Campione, J. C. (1994). Guided discovery in community of learners. In J. McGilly (Ed.), Classroom Lessons: Integrating Cognitive Theory (pp. 229-270). Cambridge, Mass.: MIT Press.

Bucat, B., \& Shand, T. (1996). Thinking Tasks in Chemistry, Teaching for Understanding. Perth: University of Western Australia.

Collins, A., Brown, J. S., \& Newman, S. E. (1989). Cognitive apprenticeship: Teaching the crafts of reading, writing and mathematics. In L. B. Resnick (Ed), Knowing, Learning and Instruction: Essays in Honour of Robert Glaser (pp. 453-494). Hillsdale, New Jersey: Lawrence Erlbaum.

Dart, B. (1997). Adult learners' metacognitive behaviour in higher education. In P. Sutherland (Ed), Adult Learning: A Reader (pp. 30-43). London: Kogan Page.

De Corte, E., Verschaffel, L., \& Op'Teynde, P. (2000)). Self-regulation: A characteristic goal of mathematics education. In M. Boekaerts, P. R. Pintrich \& M. Zeidner (Eds), Handbook of Self-Regulation (pp. 687-722). San Diego: Academic Press.

Elen, J., \& Lowyck, J. (1999). Metacognitive instructional knowledge: Cognitive mediation and instructional design. Journal of Structural Learning and Intelligent Systems, 13(3), 145-169.

Everson, H. T., \& Tobias, S. (1998). The ability to estimate knowledge and performance in college: A metacognitive analysis. Instructional Science, 26(1-2), 65-79.

Flavell, J. H. (1976). Metacognitive aspects of problem solving,. In L. B. Resnick (Ed), The Nature of Intelligence (pp. 231-235). New Jersey: Lawrence Erlbaum.

Gabel, D. L., \& Bunce, D. M. (1994). Research on problem solving: Chemistry. In D. L. Gabel (Ed), Handbook of Research on Science Teaching and Learning (pp. 301326). New York: Macmillan Publishing Company. 
Gourgey, A. F. (1998). Metacognition in basic skills instruction. Instructional Science,, 26(1-2), 81-96.

Gredler, M. E. (1997). Learning and Instruction: Theory into Practice. New Jersey: Merrill, Prentice Hall.

Hanson, D., \& Wolfskill, T. (2000). Process workshops - a new model for instruction. Journal of Chemical Education, 77(1), 120-130.

Hatano, G., \& Inagaki, K. (1986). Two courses of expertise. In H. A. H. Stevenson \& K. Hakuta (Eds), Child Development and Education in Japan (pp. 262-272). New York: Freeman.

Hedberg, J., Harper, B., Lockyer, L., Ferry, B., Brown, C., \& Wright, R. (1988). Supporting learners to solve ill-structured problems. In R. M. Corderoy (Ed), Flexibility - the next wave? Proceedings of ASCILITE Conference 98 (pp. 317-327). Wollongong: University of Wollongong. [verified 16 Mar 2001, - partial copy only] http: / / www.ascilite.org.au/ conferences / wollongong98/asc98$\mathrm{pdf} /$ hedbery.pdf

Hobden, P. (1998). The role of routine problem tasks in science teaching. In B. J. Fraser and K. G. Tobin (Eds), International Handbook of Science Education (Vol 1, pp. 219-231). Dordrecht: Kluwer Academic Publishers.

Jacobs, J. E., \& Paris, S. G. (1987). Children's metacognition about reading: Issues in definition, measurement and instruction. Educational Psychologist, 22, 255-278.

Kozma, R., Chin, E., Russell, J. \& Marx, N. (2000). The roles of representations and tools in chemistry and their implications for chemistry teaching. The Journal of the Learning Sciences, 9(2), 105-143.

Lin, X., Hmelo, C., Kinzer, C. K. \& Secules, T. J. (1999). Designing technology to support reflection. Educational Technology Research and Development, 47(3), 43-62.

Masui, C. \& De Corte, E. (1999). Enhancing learning and problems solving skills: Orienting and self-judging, two powerful and trainable learning tools. Learning and Instruction, 9(6), 517-542.

Mayer, R. E. (1998). Cognitive, metacognitive and motivational aspects of problem solving. Instructional Science, 26(1-2), 49-63.

McAllister, H. C. (1998). 21st Century problem solving. [viewed 26 May 2000, verified 16 Mar 2001] http: / / www.suremath.com/suremath/suremath/home1.html

McLoughlin, C. \& Oliver, R. (1998). Planning a telelearning environment to foster higher order thinking. Distance Education, 242-264.

McLoughlin, C., Baird, J., Pigdon, K. \& Woolley, M. (2000). Fostering teacher inquiry and reflective learning processes through technology enhanced scaffolding in a multimedia environment. In J. Bourdeau \& R. Heller (Eds), Ed Media-Ed Telecom World Conference on Educational Multimedia and Hypermedia (pp. 149-155). Charlottesville, VA: AACE. 
McLoughlin, C., \& Luca, J. (2000). Cognitive engagement and higher order thinking through computer conferencing: We know why but do we know how? In A. Herrmann \& T. Kulski (Eds), Flexible Futures in Tertiary Learning (pp. 219234). Perth: Curtin University of Technology. [online version is similar, verified 16 Mar 2001] http: / / cleo.murdoch.edu.au/ confs/tlf / tlf2000 / mcloughlin.html

Metcalfe, J., \& Shimamura, A. P. (1994). Metacognition: Knowing about Knowing. Cambridge, Mass: MIT Press.

Perry, W. G. (1970). Forms of Intellectual and Ethical Development in College Years. New York: Holt, Rinehart and Winston.

Schoenfeld, A. H. (1985). Mathematical Problem Solving. New York: Academic Press.

Schoenfeld, A. H. (1992). Learning to think mathematically: Problem solving, metacognition and sense making in mathematics. In D. A. Grouws (Ed), Handbook of Research on Mathematics Teaching and Learning (pp. 334-370). New York: Macmillan.

Schraw, G. (1998). Promoting general metacognitive awareness. Instructional Science, 26(1-2), 113-125.

Schraw, G., \& Dennison, R. S. (1994). Assessing metacognitive awareness. Contemporary Educational Psychology, 19, 460-475.

Sleet, R., Hager, P., Logan, P., \& Hooper, M. (1996). Broader Skill Requirements of Science Graduates. Sydney: University of Technology, Sydney.

Tergan, S. (1997). Conceptual and methodological shortcomings in hypertext / hypermedia design and research. Journal of Educational Computing Research, 16(3), 209-237.

Volet, S., McGill, T. \& Pears, H. (1995). Implementing process-based instruction in regular university teaching: Conceptual, methodological and practical issues. European Journal of Psychology of Education, 10, 385-400.

Volet, S. E. (1991). Modelling and coaching of relevant metacognitive strategies for enhancing university students' learning. Learning and Instruction, 1, 319-336.

Vye, N. J., Schwartz, D. L., Bransford, J. D., Barron, B. J., \& Zech, L. (1998). SMART environments that support monitoring, reflection and revision. In D. J. Hacker, J. Dunlosky \& A. C. Graesser (Eds), Metacognition in Educational Theory and Practice (pp. 305-346). Mahwah, New Jersey: Lawrence Erlbaum Associates.

Woodcock, D. (1995). Problem Solving in Chemistry, The A thru E Approach. [unknown 16 Mar 2001] http: / / oksw01.okanagan.bc.ca/chem/probsol/ps_AE.html

Zeegers, P., Martin, L., \& Martin, C. (1998). Using learning to learn strategies to enhance student self-regulated learning in first-year chemistry. Paper presented at the Third Pacific Rim Conference, Auckland.

Rowan W. Hollingworth

Chemistry, School of Physical Sciences and Engineering, University of New England, Armidale NSW 2351, Australia. rholling@metz.une.edu.au Catherine McLoughlin, Teaching and Learning Centre, University of New England, Armidale NSW 2351, Australia.mcloughlin@metz.une.edu.au 